\title{
Responses of the Cardiovascular System to Carotid Sinus Nerve Stimulation
}

\author{
GUNNAR SEDIN \\ From the Institute of Physiology and Medical Biophysics, Biomedical Center, \\ University of Uppsala, Sweden
}

\begin{abstract}
The changes in blood pressure, heart rate, cardiac output and blood flow in the femoral and common carotid arteries on carotid sinus nerve stimulation (CSNS) were studied in chloralose anaesthetized dogs, both with spontaneous heart hythm and during atrial pacing. Stimulation of the sinus nerves with impulse trains and with impulses of constant frequency had almost equal effects on the blood pressure. The former had a greater effect on the heart rate; these findings verified earlier observations. The reductions in cardiac output followed those in heart rate. During atrial pacing the stroke volume was reduced on CSNS. The total peripheral resistance, regional peripheral resistances and input impedance of the vascular bed of the femoral artery were calculated. The initial effects of CSNS varied in relation to the prestimulation total peripheral resistance and to stimulation frequency. Differences between stimulation with a constant frequency and the intermittent types, with the same number of impulses per cardiac cycle, were negligible as regards effects on stroke volume, blood flow and regional vascular resistances. CSNS caused changes in input impedance of the vascular bed of the femoral artery which were very similar to those observed earlier on intraarterial injection of vasodilator drugs.

The different effects of intermittent and constant frequency CSNS on the heart rate in dogs with intact vagal nerves and no clamping of the common carotid arteries might be caused by asymmetries in the autonomic effects on the S.A. node. The neurophysiological mechanisms are discussed. It is deduced that greater reductions in blood pressure with intermittent stimulation are only obtained in the pre-existence of a high sympathetic tone.
\end{abstract}

\section{NTRODUCTION}

Extensive studies of the carotid sinus reflex [for eview see (24), (35)] and of its blood pressure regulating properties $(36,40,56)$ have been made during the last fifty years.

In experimental investigations of centrally mediated reflex responses, reproducible and quanti- fiable input signals to the central nervous system can be obtained by applying electrically induced nerve impulses $(31,45)$. Using electrical stimulation of the carotid sinus nerves in chloralose anaesthetized dogs, Öberg \& Sjöstrand (45) found that the carotid sinus reflex had proportional and derivating gain characteristics. They also observed a more damped blood pressure response on modulation of the input signal. In a subsequent study they (46) showed that the afferent sinus nerve information could cause bandwidth limitation of the blood pressure regulating system because of its pulsating nature. Stimulation impulse trains applied to the sinus nerves during systole resulted in a greater percentual blood pressure reduction than constant frequency stimulation in dogs with clamped common carotid arteries.

Jonzon et al. (29) found that the maximal blood pressure reducing effect of carotid sinus nerve stimulation (CSNS) was obtained at only 5-10 stimulation impulses per cardiac cycle. They also noted that stimulation of the sinus nerves with impulse trains caused a greater reduction in heart rate than constant frequency stimulation. This observation was not made, however, during experimental 'clamping' of the common carotid arteries. The differences in the effects on the blood pressure and heart rate of stimulating the carotid sinus nerves at a constant frequency and with intermittent impulse trains have not yet been fully explained.

The aim of this study was to elucidate the differences in effector response to the three impulse patterns used in the previous investigation (29), by measurements of the cardiac output and blood flows and by calculations of the vascular resistance and vascular input impedance. 


\section{METHODS}

Animals, anaesthesia and preparation

The experiments were performed on endotracheally intubated mongrel dogs of both sexes, weighing between 15 and $25 \mathrm{~kg}(\operatorname{dogs} 1-7)$ or $30-32 \mathrm{~kg}(\operatorname{dogs} 8$ and 9). Young healthy dogs were used throughout, their ages not exceeding 2 years.

Anaesthesia was induced with 5 per cent thiopental sodium (Pentothal Sodium ${ }^{*}$, Abbott S. A., Belgium) $(0.025 \mathrm{~g} / \mathrm{kg} \mathrm{b}$.w.) and maintained by continuous infusion of 0.72 per cent chloralose (E. Merck AG, Darmstadt, BRD) at body temperature (cf. 2, 10).

High-frequency positive-pressure ventilation (HFPPV) (28) with insufflation of humidified air 80 times per minute with an insufflation time of $20 \%$ of the period time was instituted immediately after intubation. At the same time a slow infusion of $10 \%$ invertose (Inverdex ${ }^{\mathbb{1}}$, Pharmacia AB, Uppsala, Sweden), ${ }^{1}$ to which was added $100 \mathrm{ml} 0.6 \mathrm{M}$ bicarbonate solution per litre, was started.

Care was taken to maintain a constant body temperature of $38^{\circ} \mathrm{C}$, adequate ventilation and a normal acid-base status. Arterial $\mathrm{pH}, \mathrm{PCO}_{2}, \mathrm{PO}_{2}$, base excess and standard bicarbonate $\left(\mathrm{HCO}_{3}^{-}\right)$were determined repeatedly during the preparation (and corrected if necessary) and before every experimental sequence. $\mathrm{PCO}_{2}$, base excess and $\mathrm{HCO}_{3}^{-}$were determined by means of the Siggaard-Andersen Curve Nomogram for human blood, using the Astrup technique. ${ }^{2}$

The common carotid arteries and the carotid sinus nerve bundles were dissected free and the left superior thyroid artery was ligated. Electrodes were applied on the intact nerve bundles close to the carotid sinus. To minimize spread of stimulation current, the nerve bundles and the electrodes outside them were covered by a thin plastic sheath.

The paws were fixed with elastic bands, causing compression but no stasis

A transvenous pacemaker electrode was inserted from the right jugular vein to the right atrium. For radiographic control during the introduction of the catheters and pacemaker electrode a mobile fluoroscopy unit with an image intensifier (BV 21S, Philips AB, Stockholm, Sweden) ${ }^{3}$ was used. Isopaque ${ }^{\$}$ (Nyegaard \& Co A/S, Oslo, Norway) was employed as contrast medium.

\section{Electrodes and stimulation}

In order to achieve effective stimulation with impulses of low voltage amplitude, platinized platinum electrodes (platinum black) were used. The electrodes, which were placed at a mutual distance of $3.5 \mathrm{~mm}$, were in the form of

1 Inverdex was kindly supplied by Pharmacia AB, Uppsala, to whom the author expresses his thanks.

2 The prestimulation mean arterial $\mathrm{pH}$ was 7.42 (S.E. 0.01, $n=42$ ), $\mathrm{P}_{\mathrm{CO}_{2}} 29.2 \mathrm{mmHg}$ (S.E. 0.7), $\mathrm{P}_{2} 105 \mathrm{mmHg}$ (S.E. 1.1), BE $-4.4 \mathrm{mEq} / \mathrm{l}(\mathrm{S} . \mathrm{E} .0 .4)$ and $\mathrm{HCO}_{3}{ }^{-} 18.5 \mathrm{mEq} / 1$ (S.E. 0.4). During pacing of the heart pH was 7.36 (S.E. $0.01, n=21$ ), $\mathrm{PCO}_{2} 33 \mathrm{mmHg}$ (S.E. 1.0) and $\mathrm{PO}_{2} 97 \mathrm{mmHg}$ (S.E. 4.0). Base excess and $\mathrm{HCO}_{3}$ were unchanged.

3 The author wishes to thank Philips $A B$ for placing the equipment at his disposal. bands, $1 \mathrm{~mm}$ broad and $0.1 \mathrm{~mm}$ thick. The interelectrode impedance was 500-800 ohms (cf. 29, 46).

Three different types of electrical stimulation of the carotid sinus nerves were used, namely constant frequency stimulation (A) and two types of ECG-triggered impulse bursts (B and $C$ ). In stimulation type $B$ there was a constant frequency within the train (duration $150 \mathrm{~ms}$ ) while in type $C$ the frequency increased linearly within the train (29).

Stimulation impulses with a duration of $0.5 \mathrm{~ms}$ were given by two stimulators with isolated output (Gated Pulse Generator, Type 2521 and 2533, Devices Instr. Ltd., Welwyn Garden City, Hertfordshire, England). The stimulation impulses applied to the sinus nerves were delayed so as to displace the phases of the stimulator output signals $0.1 \mathrm{~ms}$ in relation to each other, thereby preventing 'cross-stimulation' between the right and the left electrodes $(45,63)$.

The impulse trains were ECG-synchronized and delayed to coincide with the systolic phase of the arterial pulse wave. In all stimulation types the same number of impulses per cardiac cycle was given and the number of impulses per impulse train was monitored with an electronic counter (cf. 29).

In experiments with transvenous pacing of the heart a Goetz bipolar pacemaker electrode (type 5652, USCI, Glens Falls, New York, USA) was used. Square wave impulses with a duration of $2 \mathrm{~ms}$ and amplitudes of 1.5-3 volts were generated by a stimulator with isolated output (E \& M Instrument Co., Inc., Houston, Texas, USA).

\section{Measurements}

The arterial blood pressure (dogs 1-7), central venous pressure and arterial blood gases were measured as described in a previous article (28). The heart rate was recorded by an instantaneous ratemeter (type 2751, Devices Sales Ltd., Welwyn Garden City, England). The instruments for amplification and recording were also the same as in the previous study.

The catheter for measurement of arterial blood pressure and the thermistor for cardiac output measurements were both introduced from the right femoral artery to a position in the thoracic part of the descending aorta. The catheter for measurement of central venous pressure (dogs 1 and 2) was introduced from the right femoral vein.

In dog 8 the arterial blood pressure was measured at the bifurcation of the abdominal aorta via a catheter (Radicath aorta-femoral, Radiplast, Uppsala, Sweden) introduced via a muscle branch of the right femoral artery. Control measurement of the blood pressure was performed via an identical catheter introduced through a muscle branch of the left femoral artery and placed with its tip $2 \mathrm{~cm}$ distal to the flow transducer (see below). To minimize interference to flow in the artery the catheter was inserted only about 1 $\mathrm{mm}$ into the arterial lumen. In dog 9 both pressures were recorded in all experiments. Both catheters were connected to transducers (Statham P23DC, Statham Laboratories, Inc., Puerto Rico). Control measurement of frequency characteristics showed a constant gain in the pressure measurement system at frequencies below $25 \mathrm{~Hz}$.

The blood flow in the left common carotid artery and in the left femoral artery was recorded continuously, using a 
two-channel pulsed-logic electromagnetic blood flowmeter (BL610, Biotronex Laboratory, Inc., Silver Spring, Maryland, USA). Blood flow transducers with a luminal diameter of 2.5-3.5 mm were applied to the left common carotid artery just above the mediastinum (dogs 1-7) and to the left femoral artery distal to the inguinal ligament (dogs 1-9). All arterial branches in the vicinity of the flow transducers were ligated close to the main artery and severed. To maintain contact between the transducer electrodes and arterial wall the transducer size was chosen such as to produce very slight constriction of the artery. The artery and transducer were kept moist by covering them with pads soaked in saline. Zero flow was obtained by occluding the artery $3-4 \mathrm{~cm}$ distal to the flow transducer. The transducer balance and zero flow were checked before every experimental sequence.

The mean blood flow was measured in dogs $1-7$. The phasic blood flow in the femoral artery was measured in dogs 8 and 9 with a maximum frequency response setting (band width $0-100 \mathrm{~Hz}(-3 \mathrm{~dB})$ ).

The flow transducers were calibrated at the end of the experiments on each animal. Blood taken from the dog was used as calibration fluid and the haematocrit was checked to see that it accorded (maximum deviation $\pm 2 \%$ ) with that measured during the experiment (11). The arterial segments on which the transducers had been applied were excised and mounted in a calibration holder, enabling the length and thereby the wall thickness to be maintained (3). Collapse of the artery was prevented by application of positive pressure to the outlet. On calibration of a flow transducer in dog 9 the standard error of the mean was $0.23 \mathrm{ml} / \mathrm{min}(n=7)$ and the coefficient of variation $3.5 \%$.

Cardiac output was measured by the thermodilution method, using a computer with direct digital evaluation without influence of recirculation (Herzzeitvolumenmessgerät, August Fischer KG, Göttingen, BRD; cf, 15, 28). At every cardiac output measurement, $10 \mathrm{ml}$ of $0.9 \% \mathrm{NaCl}$ at $22^{\circ} \mathrm{C}$ were injected through a silicone catheter (dead space $0.9 \mathrm{ml}$ ) placed with its tip in the pulmonary artery. The registration thermistor was placed in the descending thoracic aorta.

\section{Experimental procedure}

CSNS was performed for 12 min with each of stimulation types A, B and C. Five and 15 stimulation impulses (imp)/ cardiac cycle were used as no further blood pressure reduction is obtained above 5-10 imp/cardiac cycle and no further reduction in heart rate above $15 \mathrm{imp} /$ cardiac cycle (29). The arterial blood pressure, heart rate, and blood flow in the left femoral and left common carotid arteries were recorded continuously. Arterial $\mathrm{pH}, \mathrm{PCO}_{2}$ and $\mathrm{PO}_{2}$ were measured before, and in most experiments also during, stimulation. Cardiac output was measured before every experimental sequence (in triplicate), checked before the start of stimulation (single measurement) and measured again after $10 \mathrm{~min}$ of stimulation (in duplicate).

The heart rate was kept constant at 180 beats/min during three experiments in each $\operatorname{dog}$ (stimulation types $A$, $B$ and $C ; 15 \mathrm{imp} /$ cardiac cycle). When pacing of the heart was not successful a short period of CSNS made the heart follow the pacemaker in all cases.

\section{Calculations}

Aortic mean blood pressure was calculated as described previously (29). The mean blood pressure in the abdominal aorta or femoral artery was determined by integrative methods.

Total peripheral resistance (TPR) was calculated as the ratio of mean aortic blood pressure to cardiac output $(\mathrm{mmHg} / \mathrm{ml} / \mathrm{min})$. As the central venous pressure is low and only shows negligible variations during HFPPV, it was set at zero in the calculations [see (28) and Results].

Peripheral resistance in regional vascular beds was calculated as the ratio of mean blood pressure to mean blood flow $(\mathrm{mmHg} / \mathrm{ml} / \mathrm{min})$.

The input impedance of the vascular bed of the femoral artery was calculated as the ratio between each of the harmonic frequency components of the oscillatory pressure and flow according to McDonald (43). The harmonic frequency components and phase angle were calculated by numerical Fourier analysis with 24 segments per cardiac cycle (44).

Unless otherwise stated, the percentual changes reported are the mean values for changes in seven dogs. All statistically significant differences mentioned in the text were obtained by testing paired observations (Student's $t$-test).

\section{RESULTS}

\section{Transient responses to CSNS}

The magnitudes of initial reductions in blood pressure and heart rate during the first min of CSNS have been reported in previous articles (cf. 29, 30, 31).

The initial responses of the blood flow in the femoral artery show greater relative variations, both in magnitude and in direction, than those of the blood pressure. As the initial effects of CSNS seemed to be related to the prestimulation TPR, 3 dogs (1,3 and 7) with different prestimulation TPR will be described in some detail below. The prestimulation cardiac output and TPR are presented in Table I.

CSNS with 5 imp/cardiac cycle. All dogs except dog 3 showed a transient increase in blood flow in the femoral artery, with extreme responses in dogs 1 and 7. Fig. 1 presents the changes in arterial mean blood pressure, arterial puise pressure, heart rate and blood flow in the left femoral artery in dogs 1, 3 and 7 during the first min of CSNS at a constant frequency (type A).

The initial reduction in blood pressure was greater in dog 1 than in dogs 3 and 7 on stimulation at 5 imp/cardiac cycle. In all dogs the pulse pressure decreased during the first 9 s of stimulation; in dog 1 this was followed by a marked but transient in- 
Table I. Body weight (b.w.kg) and prestimulation total peripheral resistance (TPR; $\mathrm{mmHg} / \mathrm{ml} / \mathrm{min})$ and cardiac output $(\mathrm{CO} ; 1 / \mathrm{min})$ in dogs 1,3 and 7

\begin{tabular}{|c|c|c|c|c|c|}
\hline \multirow[b]{2}{*}{$\begin{array}{l}\text { Dog no. } \\
\text { (b.w.kg) }\end{array}$} & \multirow[b]{2}{*}{$\begin{array}{l}\text { Expt. with } \\
\text { stim. type }\end{array}$} & \multicolumn{2}{|c|}{ Before expt. with $5 \mathrm{imp}$. } & \multicolumn{2}{|c|}{ Before expt. with $15 \mathrm{imp}$. } \\
\hline & & $\begin{array}{l}\text { Prestim. CO } \\
\text { (1/min) }\end{array}$ & $\begin{array}{l}\text { Prestim. TPR } \\
(\mathrm{mmHg} / \mathrm{ml} / \mathrm{min})\end{array}$ & $\begin{array}{l}\text { Prestim. CO } \\
\text { (1/min) }\end{array}$ & $\begin{array}{l}\text { Prestim TPR } \\
(\mathrm{mmHg} / \mathrm{ml} / \mathrm{min})\end{array}$ \\
\hline $1(15)$ & $\begin{array}{l}\mathrm{A} \\
\mathrm{B} \\
\mathrm{C}\end{array}$ & $\begin{array}{l}3.32 \\
3.32 \\
3.32\end{array}$ & $\begin{array}{l}0.05 \\
0.05 \\
0.05\end{array}$ & $\begin{array}{l}3.32 \\
3.32 \\
3.32\end{array}$ & $\begin{array}{l}0.06 \\
0.05 \\
0.05\end{array}$ \\
\hline $3(25)$ & $\begin{array}{l}\mathrm{A} \\
\mathrm{B} \\
\mathrm{C}\end{array}$ & $\begin{array}{l}2.28 \\
2.28 \\
2.28\end{array}$ & $\begin{array}{l}0.07 \\
0.07 \\
0.07\end{array}$ & $\begin{array}{l}2.04 \\
2.04 \\
2.04\end{array}$ & $\begin{array}{l}0.07 \\
0.08 \\
0.07\end{array}$ \\
\hline $7(19)$ & $\begin{array}{l}\mathrm{A} \\
\mathrm{B} \\
\mathrm{C}\end{array}$ & $\begin{array}{l}1.95 \\
1.87 \\
1.97\end{array}$ & $\begin{array}{l}0.10 \\
0.10 \\
0.09\end{array}$ & $\begin{array}{l}2.30 \\
2.26 \\
2.27\end{array}$ & $\begin{array}{l}0.08 \\
0.09 \\
0.08\end{array}$ \\
\hline
\end{tabular}

crease. In dog 3 minor changes in pulse pressure occurred, while in $\operatorname{dog} 7$ there was a gradual reduction.

A very rapid reduction in heart rate was noted in dogs 1 and 3 within the first $3 \mathrm{~s}$. In dog 1 this was followed by an increase, and after $1 \mathrm{~min}$ a value only slightly lower than the prestimulation level was attained. In dogs 3 and 7 the greatest heart rate reduction occurred later but the reduction was more persistent.

The blood flow in the femoral artery was initially reduced in $\operatorname{dog} 1$, the reduction coinciding with the initial decrease in heart rate. Although the blood pressure was falling there was a marked increase in blood flow from 6 to $20 \mathrm{~s}$ after the start of stimulation. A smaller but distinct transient increase in flow also took place in $\operatorname{dog} 7$, while in dog 3 the blood flow slowly decreased. The transient increase in blood flow in dogs 2, 4, 5 and 6 was smaller than that in dog 1 and equal to or somewhat greater than that in $\operatorname{dog} 7$.

CSNS with $15 \mathrm{imp} / \mathrm{cardiac}$ cycle. Compared with CSNS at $5 \mathrm{imp} /$ cardiac cycle, in dogs 3 and 7 the initial effects on the blood pressure were more marked on CSNS at $15 \mathrm{imp} /$ cardiac cycle. The initial heart rate reduction was more rapid and more pronounced and was accompanied by a reduction in blood flow in the femoral artery during the very first seconds in all 3 dogs. The pulse pressure increased initially in $\operatorname{dogs} 3$ and 7 , while in dog 1 there was an initial reduction followed by a transient increase. The blood flow in the femoral artery changed in the same way as on stimulation at $5 \mathrm{imp} /$ cardiac cycle.
CSNS with 5 and 15 imp/cardiac cycle. At 5 imp/cardiac cycle as an average for all dogs the initial reductions in heart rate in relation to the prestimulation values were 19,20 and 23 per cent for stimulation types A, B and C, respectively. At $15 \mathrm{imp} /$ cardiac cycle the corresponding reductions were 31,28 and $34 \%$.

The mean central venous pressure. measured in 2 dogs, increased by about $1 \mathrm{mmHg}$ during the initial maximal reduction in heart rate and reached the prestimulation value within $1 \mathrm{~min}$.

The initial changes in blood flow in the carotid artery were less oscillatory than in the femoral artery and the blood flow reduction followed the reduction in blood pressure. However, at higher stimulation frequencies a steep reduction was obtained within the first $6 \mathrm{~s}$.

CSNS with 15 imp/cardiac cycle during cardiac pacing. In the experiments presented in Fig. 2 the heart rate was kept constant by atrial pacing ( 180 beats/min), thereby eliminating the effects of CSNS on the heart rate. The atrial pacing caused an average reduction of the mean blood pressure of 23 $\mathrm{mmHg}(p<0.025)$ but no changes in stroke volume. As illustrated in Fig, 2 (left part) the pulse pressure varied considerably during the first $10 \mathrm{~s}$ of stimulation in dogs 1 and 7 , as in these dogs the heart did not follow the very first pacemaker impulses delivered after the start of CSNS. In dog 3 the pulse pressure increased after a small initial reduction; all dogs showed an increase 18-25 s after the start of stimulation, followed by a reduction. The decrease in blood flow seen in dogs 1 and 7 during the first $6 \mathrm{~s}$ 

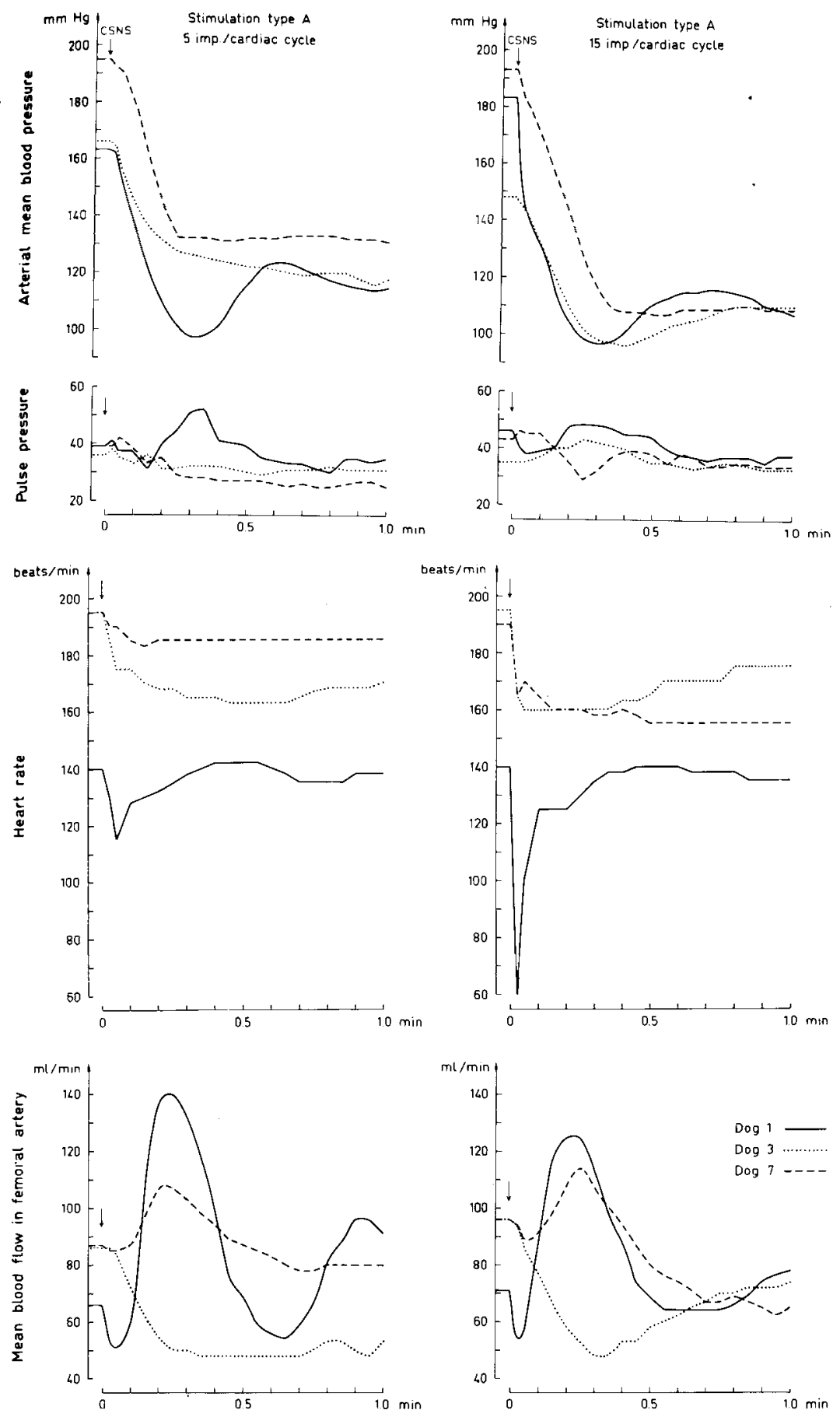

Fig. 1. Initial responses in arterial mean blood pressure, pulse pressure, heart rate and mean blood flow in the femoral artery on CSNS with stimulation type $A$ at 5 and $15 \mathrm{imp} /$ cardiac cycle in dogs 1,3 and 7.

did not occur in $\operatorname{dog} 3$, in which the heart rate strictly followed the pacemaker the whole time (cf. Fig. 1). The initial changes in blood flow were fairly similar to those seen in Fig. 1, although the heart rate reduction was eliminated. However, the tran- sient increase in blood flow was smaller and only in dog 1 did the flow exceed the prestimulation level. The transient increase in blood flow in dog 1 was smaller with stimulation type $C$ (right part of Fig. 2) than with type A. 

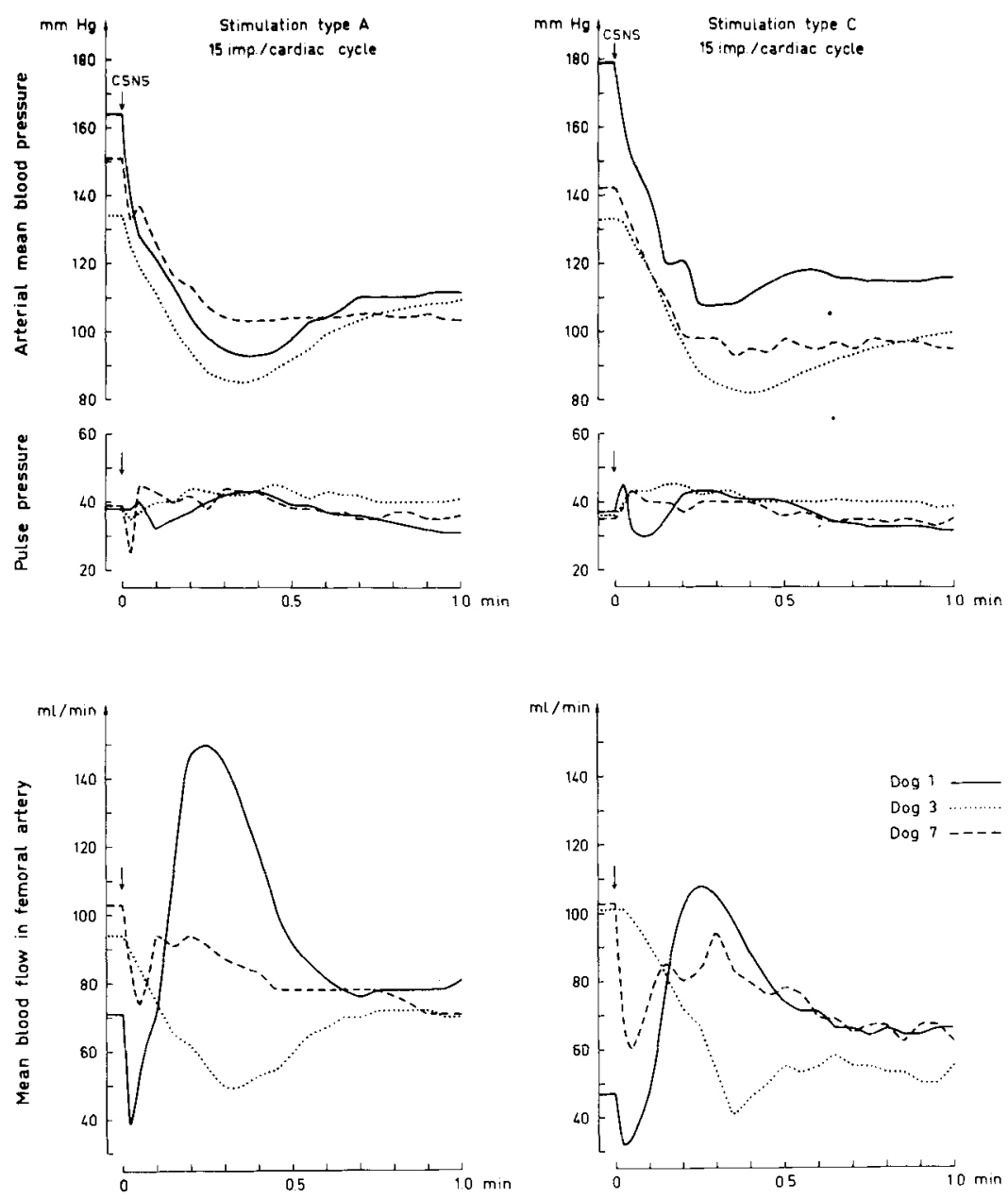

Fig. 2. Initial responses of arterial mean blood pressure, pulse pressure and mean blood flow in the femoral artery to CSNS with stimulation types $\mathrm{A}$ and $\mathrm{C}$ at 15 imp/cardiac cycle in dogs 1 , 3 and 7 during atrial pacing $(180 / \mathrm{min})$.

The adaptation period during CSNS

Irrespective of stimulation type the blood pressure seemed to stabilize about $1 \mathrm{~min}$ after the start of CSNS. However, when $5 \mathrm{imp} /$ cardiac cycle were used the mean blood pressure slowly decreased for a further $3 \mathrm{~min}$. A stable period occurred at about 2 min after the start of stimulation. On stimulation at $15 \mathrm{imp} /$ cardiac cycle the mean blood pressure slowly increased $(6 \mathrm{mmHg} / 8 \mathrm{~min})$ after the initial oscillations. The same rise in mean blood pressure during CSNS was noted when the heart rate was kept constant by atrial pacing.

Fig. 3 shows the heart rate changes during $10 \mathrm{~min}$ of CSNS and in the $48 \mathrm{~s}$ following the end of the stimulation period. At $5 \mathrm{imp} / \mathrm{cardiac}$ cycle the heart rate was relatively stable during the 2 nd minute of stimulation and in that period the heart rate reduction from the prestimulation value was about the same with all three types of stimulation. After $2 \mathrm{~min}$ a further reduction, more evident with the intermittent types of CSNS, occurred. At $15 \mathrm{imp} /$ cardiac cycle the increase in heart rate after the initial reduction differed between the stimulation types. The lowest heart rate after the initial reduction was attained on stimulation with type $C$, while type $A$ gave the highest heart rate. The differences in heart rate persisted throughout CSNS, but diminished with time.

After the initial reduction, the mean blood flow in the carotid artery stabilized at a new level within 3 min and then showed only minor changes. With all stimulation types the mean blood flow in the femoral artery displayed greater oscillations during the first $1.5 \mathrm{~min}$. It was stable for $30 \mathrm{~s}$ at about $2 \mathrm{~min}$ after the start of stimulation and after $3 \mathrm{~min}$ it showed no tendency to change. 

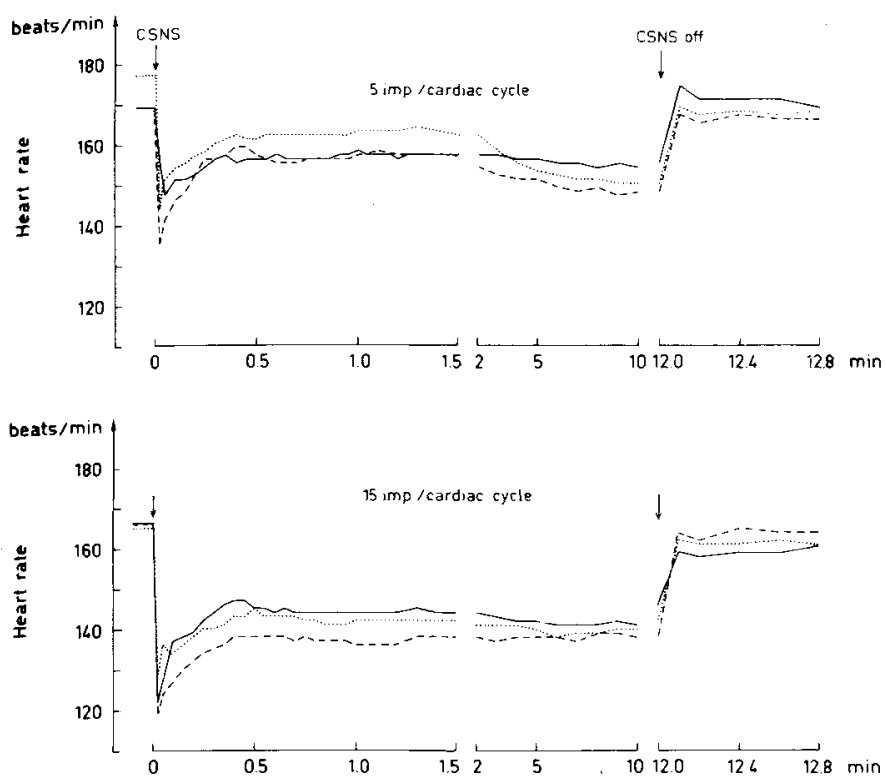

Fig. 3. Heart rate on CSNS with stimulation types $A(-), B(\cdots)$ and $C(---)$ at 5 and $15 \mathrm{imp} /$ cardiac cycle.

\section{Effects of CSNS after the adaptation} period ('Steady state effects')

In the period 5-10 min after the start of stimulation the arterial blood pressure, heart rate and blood flow altered only slightly and no respirationsynchronous variations were observed. The effects of CSNS on mean blood pressure, heart rate, blood flow, cardiac output, stroke volume, total peripheral resistance, resistance in and input impedance of the vascular bed of the femoral artery are therefore reported separately for this period and may be regarded as free from adaptive phenomena.

The reductions in mean blood pressure did not differ either with respect to stimulation type or with the number of imp/cardiac cycle (Table II). During CSNS with atrial pacing smaller reductions in mean blood pressure were noted.

On CSNS at $5 \mathrm{imp} /$ cardiac cycle the heart rate reduction was smaller with constant frequency stimulation (A) than with the intermittent types (B and $\left.C ; p_{A-C}<0.05\right)$. At $15 \mathrm{imp} /$ cardiac cycle the mean differences were negligible.

The blood flow in the left common carotid artery and the femoral artery varied only slightly during the period 5-10 min after the start of stimulation. The maximal deviations from the mean value (all experiments, $n=63$ ) were $6-40 \mathrm{ml} / \mathrm{min}$ for the carotid artery and 7-29 $\mathrm{ml} / \mathrm{min}$ for the femoral artery.

At steady state during stimulation the blood flow in the left common carotid artery was $16-37 \%$ lower than the prestimulation value. The mean blood flow in the common carotid artery was $8-10 \%$ of the cardiac output before stimulation and $7-8 \%$ of the cardiac output after $10 \mathrm{~min}$ of stimulation (spontaneous heart rhythm).

The response of the femoral arterial blood flow to CSNS varied (Table II). At 5 imp/cardiac cycle the mean alteration in this blood flow ranged from an increase of $68 \%$ to a decrease of $52 \%$. As an average for all dogs there was a decrease ranging from $4.3 \%$ (stimulation type B) to $17.6 \%$ (typeA). With CSNS at $15 \mathrm{imp} /$ cardiac cycle the femoral arterial blood flow decreased in all dogs but one, the average percentual reduction ranging from 20.9 (type $\mathrm{C}$ ) to $35.0 \%$ (type A). On CSNS during cardiac pacing the average decrease in this blood flow was 19.0 (type B) -26.7 (type C) \%. The blood flow in the femoral artery comprised about the same percentual proportion of the cardiac output before and during CSNS.

When CSNS was terminated the blood flow in the common carotid artery quickly increased and was stable again within $30 \mathrm{~s}$. The corresponding blood flow response to termination of CSNS was slower in the femoral artery.

The mean reductions in cardiac output during CSNS (Table II) were $17-21 \% \quad(p<0.01)$; the greatest reduction occurring with stimulation type $\mathrm{C}$ ( $5 \mathrm{imp} /$ cardiac cycle). When the heart rate was kept constant at 180 beats/min by pacing, the mean 
Table II. Average prestimulation values and average reductions in mean blood pressure, heart rate, blood flow in the femoral artery, cardiac output, stroke volume, total peripheral resistance and resistance in the vascular bed of the femoral artery

Reductions are given both in absolute values and in per cent of the prestimulation values. Increases are presented as negative values. S. E. = standard error of the mean percentual reduction

\begin{tabular}{|c|c|c|c|c|c|c|c|c|c|}
\hline \multirow{3}{*}{$\begin{array}{l}\text { Heart rhythm ... } \\
\text { No. of impulses ... } \\
\text { Stimulation type . . }\end{array}$} & \multicolumn{6}{|c|}{ Spontaneous } & \multirow{2}{*}{\multicolumn{3}{|c|}{$\frac{\text { Cardiac pacing }}{15}$}} \\
\hline & \multicolumn{3}{|l|}{5} & \multicolumn{3}{|l|}{15} & & & \\
\hline & A & B & $\mathrm{C}$ & A & B & $\mathrm{C}$ & A & B & $\mathrm{C}$ \\
\hline $\begin{array}{l}\text { Arterial mean blood pressure } \\
\text { mean prestim. value, } \mathrm{mmHg} \\
\text { mean reduction, mmHg } \\
\text { mean reduction in per cent } \mathrm{S} \text {.E. }\end{array}$ & $\begin{array}{l}175 \\
45 \\
25.6 \\
\pm 4.1\end{array}$ & $\begin{array}{l}177 \\
45 \\
24.9 \\
\pm 2.3\end{array}$ & $\begin{array}{l}175 \\
50 \\
28.3 \\
\pm 2.9\end{array}$ & $\begin{array}{l}165 \\
51 \\
30.1 \\
\pm 4.1\end{array}$ & $\begin{array}{l}163 \\
51 \\
30.6 \\
\pm 2.3\end{array}$ & $\begin{array}{l}162 \\
49 \\
29.6 \\
\pm 3.1\end{array}$ & $\begin{array}{r}148 \\
37 \\
24.1 \\
\pm 2.8\end{array}$ & $\begin{array}{l}141 \\
33 \\
23.0 \\
\pm 1.9\end{array}$ & $\begin{array}{r}142 \\
34 \\
23.1 \\
\pm 3.7\end{array}$ \\
\hline $\begin{array}{l}\text { Heart rate } \\
\text { mean prestim. value, beats } / \mathrm{min} \\
\text { mean reduction, beats/min } \\
\text { mean reduction in per cent } S . E \text {. }\end{array}$ & $\begin{array}{l}169 \\
15 \\
8.4 \\
\pm 1.7\end{array}$ & $\begin{array}{l}177 \\
25 \\
14.9 \\
\pm 2.8\end{array}$ & $\begin{array}{c}169 \\
21 \\
12.4 \\
\pm 2.6\end{array}$ & $\begin{array}{c}164 \\
23 \\
14.9 \\
\pm 4.8\end{array}$ & $\begin{array}{l}165 \\
26 \\
16.1 \\
\pm 3.8\end{array}$ & $\begin{array}{l}166 \\
27 \\
17.1 \\
\pm 4.5\end{array}$ & $\begin{array}{r}180 \\
0 \\
0 \\
\pm 0\end{array}$ & $\begin{array}{r}180 \\
0 \\
0 \\
\pm 0\end{array}$ & $\begin{array}{r}180 \\
0 \\
0 \\
\pm 0\end{array}$ \\
\hline $\begin{array}{l}\text { Blood flow in fem. art. } \\
\text { mean prestim. value, } \mathrm{ml} / \mathrm{min} \\
\text { mean reduction, } \mathrm{ml} / \mathrm{min} \\
\text { mean reduction in per cent S.E. }\end{array}$ & $\begin{array}{l}95 \\
18 \\
17.6 \\
\pm 6.4\end{array}$ & $\begin{array}{r}91 \\
6 \\
4.3 \\
+13.2\end{array}$ & $\begin{array}{l}101 \\
18 \\
17.1 \\
\pm 4.3\end{array}$ & $\begin{array}{l}110 \\
37 \\
35.0 \\
\pm 8.5\end{array}$ & $\begin{array}{l}95 \\
25 \\
29.1 \\
\pm 3.2\end{array}$ & $\begin{array}{l}98 \\
22 \\
20.9 \\
\pm 6.2\end{array}$ & $\begin{array}{l}105 \\
26 \\
21.1 \\
\pm 7.8\end{array}$ & $\begin{array}{l}109 \\
23 \\
19.0 \\
\pm 7.3\end{array}$ & $\begin{array}{l}109 \\
27 \\
26.7 \\
\pm 6.3\end{array}$ \\
\hline $\begin{array}{l}\text { Cardiac output } \\
\text { mean prestim. value, } 1 / \text { min } \\
\text { mean reduction, } 1 / \text { min } \\
\text { mean reduction in per cent } S \text {.E. }\end{array}$ & $\begin{array}{c}2.66 \\
0.53 \\
18.6 \\
\pm 3.3\end{array}$ & $\begin{array}{c}2.63 \\
0.45 \\
17.1 \\
\pm 1.0\end{array}$ & $\begin{aligned} & 2.64 \\
& 0.57 \\
& 21.0 \\
& \pm 1.7\end{aligned}$ & $\begin{aligned} & 2.60 \\
& 0.49 \\
& 17.2 \\
&+5.0\end{aligned}$ & $\begin{array}{rl} & 2.57 \\
0.49 & 18.2 \\
\pm & 2.5\end{array}$ & $\begin{array}{r}2.59 \\
0.47 \\
17.0 \\
+3.6\end{array}$ & $\begin{aligned} & 2.78 \\
& 0.30 \\
& 10.3 \\
& \pm 2.1\end{aligned}$ & $\begin{aligned} & 2.79 \\
& 0.36 \\
& 12.2 \\
&+ 1.8\end{aligned}$ & $\begin{aligned} & 2.77 \\
& 0.40 \\
& 13.7 \\
&+2.3\end{aligned}$ \\
\hline $\begin{array}{l}\text { Stroke volume } \\
\text { mean prestim. value, } \mathrm{ml} \\
\text { mean reduction, ml } \\
\text { mean reduction in per cent } S . E \text {. }\end{array}$ & $\begin{array}{r}16.4 \\
1.4 \\
5.2 \\
\pm 6.5\end{array}$ & $\begin{array}{r}15.1 \\
-0.6 \\
-3.0 \\
\pm 5.1\end{array}$ & $\begin{array}{r}16.2 \\
1.2 \\
7.5 \\
\pm 4.4\end{array}$ & $\begin{array}{r}16.4 \\
0.6 \\
2.6 \\
\pm 5.6\end{array}$ & $\begin{array}{r}16.2 \\
0.3 \\
9.6 \\
\pm 3.1\end{array}$ & $\begin{array}{r}16.2 \\
-0.1 \\
-0.1 \\
\pm 6.6\end{array}$ & $\begin{array}{r}15.4 \\
1.6 \\
10.3 \\
\pm 2.1\end{array}$ & $\begin{array}{r}15.4 \\
2.0 \\
12.2 \\
\pm 1.9\end{array}$ & $\begin{array}{r}15.3 \\
2.2 \\
13.5 \\
\pm 2.3\end{array}$ \\
\hline $\begin{array}{l}\text { Total peripheral resistance } \\
\text { mean prestim. value, } \mathrm{mmHg} / \mathrm{ml} / \mathrm{min} \\
\text { mean reduction, } \mathrm{mmHg} / \mathrm{ml} / \mathrm{min} \\
\text { mean reduction in per cent } \mathrm{S} \text {.E. }\end{array}$ & $\begin{array}{r}0.07 \\
0.01 \\
12.9 \\
\pm 4.0\end{array}$ & $\begin{aligned} & 0.07 \\
& 0.01 \\
& 9.5 \\
&+3.1\end{aligned}$ & $\begin{array}{r}0.07 \\
0.01 \\
8.5 \\
\pm 3.9\end{array}$ & $\begin{array}{r}0.06 \\
0.01 \\
16.7 \\
\pm 4.7\end{array}$ & $\begin{array}{r}0.07 \\
0.01 \\
14.7 \\
\pm 2.7\end{array}$ & $\begin{array}{r}0.06 \\
0.01 \\
15.0 \\
\pm 2.7\end{array}$ & $\begin{array}{r}0.06 \\
0.01 \\
15.9 \\
\pm 1.9\end{array}$ & $\begin{array}{c}0.05 \\
0.01 \\
11.8 \\
\pm 1.3\end{array}$ & $\begin{array}{r}0.05 \\
0.01 \\
13.2 \\
\pm 1.3\end{array}$ \\
\hline $\begin{array}{l}\text { Resistance in vasc. bed of fem. art. } \\
\text { mean prestim, value, } \mathrm{mmHg} / \mathrm{ml} / \mathrm{min} \\
\text { mean reduction, } \mathrm{mmHg} / \mathrm{ml} / \mathrm{min} \\
\text { mean reduction in per cent } \mathrm{S} \text {.E. }\end{array}$ & $\begin{array}{r}2.3 \\
0.3 \\
12.7 \\
\pm 6.7\end{array}$ & $\begin{array}{r}2.5 \\
0.3 \\
13.7 \\
\pm 7.8\end{array}$ & $\begin{array}{r}2.0 \\
0.3 \\
14.0 \\
\pm 4.1\end{array}$ & $\begin{array}{r}1.6 \\
0.2 \\
9.4 \\
+5.9\end{array}$ & $\begin{array}{r}1.9 \\
0.2 \\
5.0 \\
+8.1\end{array}$ & $\begin{array}{r}1.8 \\
0.2 \\
7.9 \\
+7.2\end{array}$ & $\begin{array}{r}1.6 \\
0.1 \\
-2.7 \\
+10.2\end{array}$ & $\begin{array}{r}1.5 \\
0.1 \\
0.4 \\
+12.0\end{array}$ & $\begin{array}{r}1.6 \\
0.2 \\
-1.7 \\
+12.5\end{array}$ \\
\hline
\end{tabular}

reduction in cardiac output merely reflected the changes in stroke volume.

The stroke volume during CSNS (Table II) differed little from the prestimulation value. During pacing of the heart, CSNS caused reductions in stroke volume $(p<0.005)$, which were most marked with stimulation type $\mathrm{C}$.

The effects of CSNS on the total peripheral resistance are also shown in Table II. These effects were almost the same with the three stimulation types. The TPR changes during CSNS with cardiac pacing reflected the reductions in stroke volume.

The resistances in the vascular bed of the left common carotid and left femoral artery were calculated for the periods of steady state before and 5-10 min after the start of CSNS. In the latter period the mean resistance values reported were obtained from 25 determinations during the 5 minutes.

In the vascular bed of the left common carotid artery the mean prestimulation resistance range 

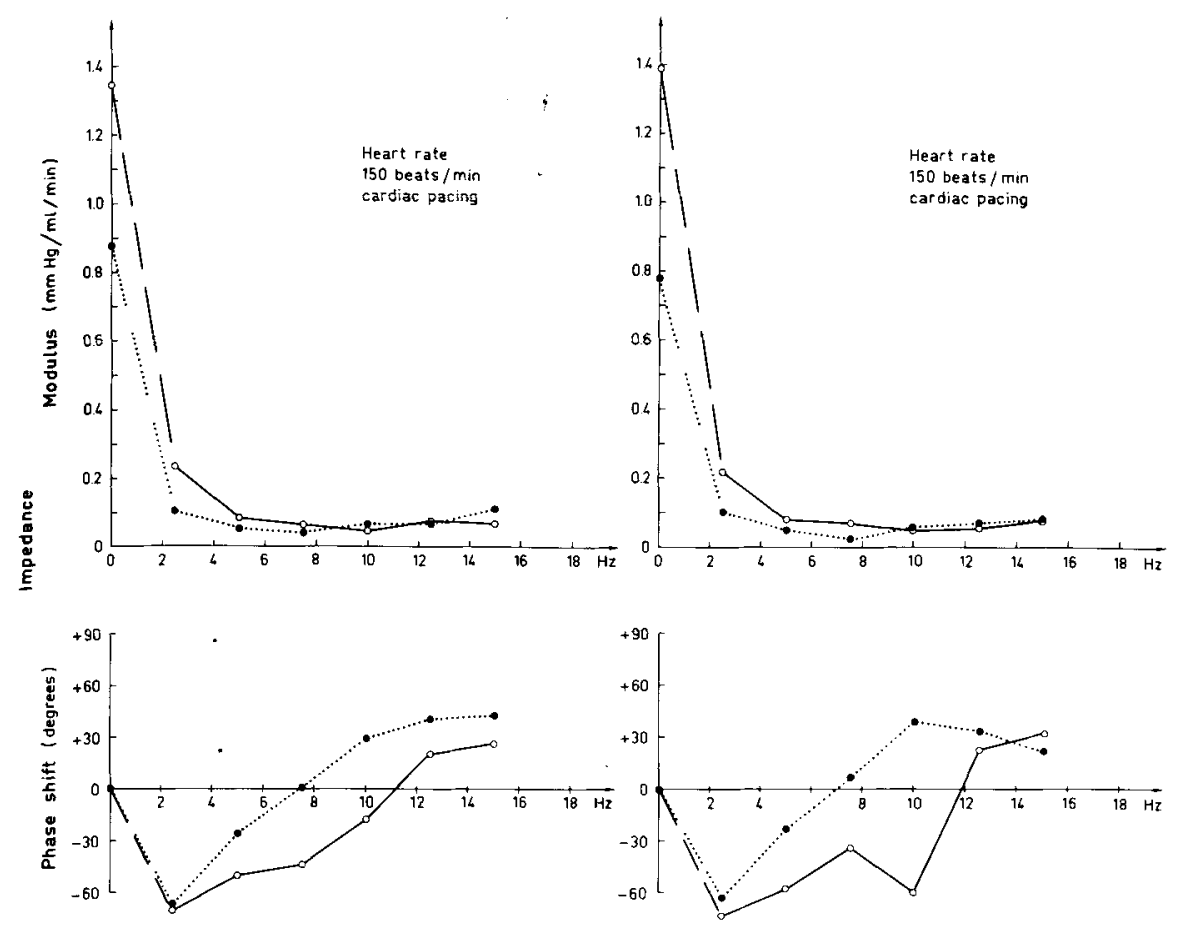

Fig. 4. Input impedance of the vascular bed of the left femoral artery in dog 8 during prestimulation steady state $(-)$ and during carotid sinus nerve stimulation $(\cdots)$ with stimulation type A (left) and stimulation type B (right). CSNS was given with $15 \mathrm{imp} /$ cardiac cycle. At fre-

quencies below the heart rate the lines in the figure are interrupted. The prestimulation mean blood pressure was $172 \mathrm{mmHg}$ in both experiments and was equally reduced to $112 \mathrm{mmHg}$ on CSNS. was $0.7-1.0 \mathrm{mmHg} / \mathrm{ml} / \mathrm{min}$. On CSNS with 5 imp/cardiac cycle an increase in resistance occurred as an average for all dogs but CSNS at 15 $\mathrm{imp} / \mathrm{cardiac}$ cycle caused no change in resistance in two dogs and minor changes in four (one dog, however, showed a marked increase in resistance). No differences with regard to stimulation types were observed.

The prestimulation resistance in the vascular bed of the femoral artery and its changes on CSNS are given in Table 11. During CSNS at $5 \mathrm{imp} / \mathrm{cardiac}$ cycle the resistance remained unchanged in three experiments where the prestimulation values were $1.6-1.7 \mathrm{mmHg} / \mathrm{ml} / \mathrm{min}$. On the average the resistance in the vascular bed of the femoral artery was reduced by $12.7-14.0 \%$ on CSNS at 5 $\mathrm{imp} / \mathrm{cardiac}$ cycle and by $5.0-9.4 \%$ on stimulation at $15 \mathrm{imp} /$ cardiac cycle. On the other hand, during pacing of the heart the mean changes in resistance were small.

The input impedance of the vascular bed of the left femoral artery was determined in dogs 8 and 9 during prestimulation and stimulation steady states under control conditions of cardiac pacing and HFPPV. Stimulation types A and B at $15 \mathrm{imp} /$ cardiac cycle were used. In measuring blood pressure and flow in a series of heart cycles minimal differences between the cycles were obtained.

Fig. 4 shows the effects of CSNS (stimulation types $A$ and $B$ ) on the input impedance of the vascular bed of the left femoral artery in $\operatorname{dog} 8$ in which the blood pressure was measured proximal to the flow transducer. In the calculations correction was made for the time delay between the sites of measurement of pressure and flow. The impedance modulus as a function of the frequency dropped rapidly and attained a minimum at the fourth harmonic. The phase shift (negative at low frequencies) became positive at a frequency of about $12 \mathrm{~Hz}$.

With both types of stimulation the vascular resistance (zero frequency) was lowered by CSNS. Impedance moduli for the first harmonics were also lower and the phase shift at low frequencies less 

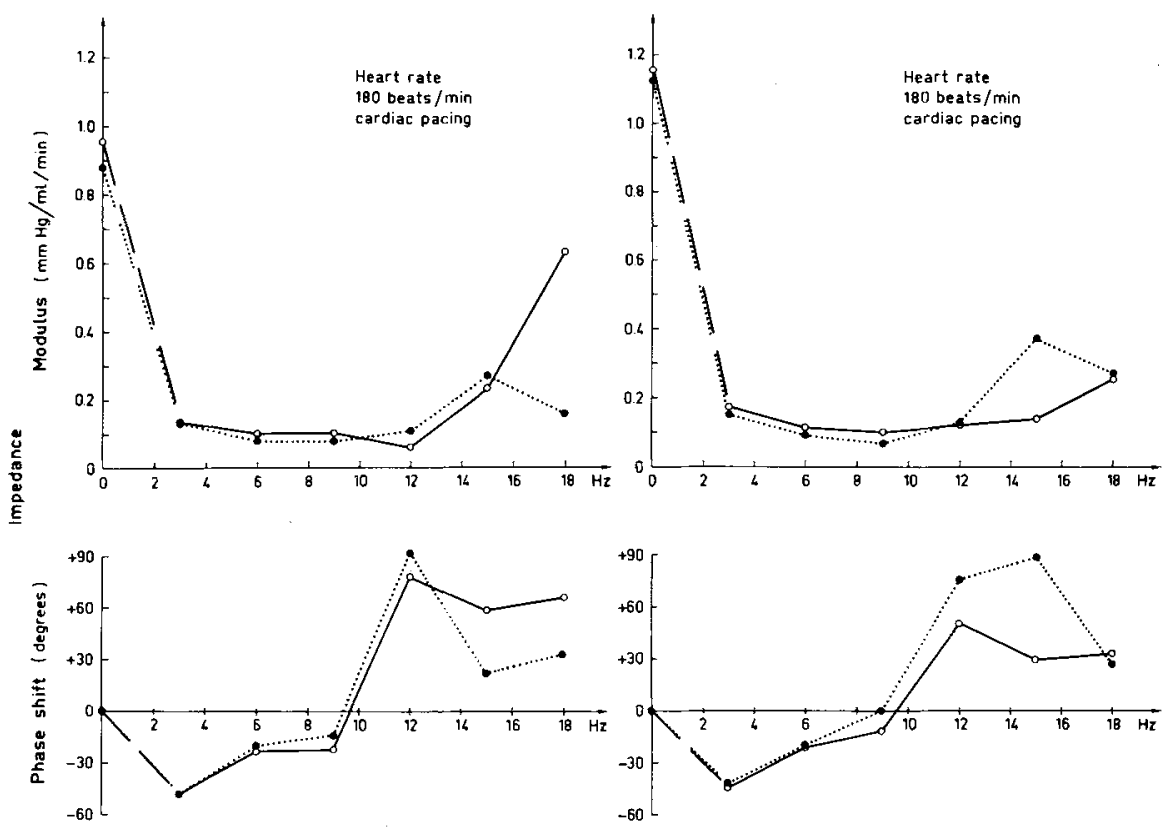

Fig. 5. Input impedance of the vascular bed of the left femoral artery in dog 9 during prestimulation steady state $(-)$ and during carotid sinus nerve stimulation $(\cdots)$ with stimulation type A (left) and stimulation type B (right). CSNS was given with $15 \mathrm{imp} /$ cardiac cycle. At fre-

quencies below the heart rate the lines in the figure are interrupted. The mean blood pressure was reduced from $129 \mathrm{mmHg}$ to $109 \mathrm{mmHg}$ with stimulation type A and from $133 \mathrm{mmHg}$ to $110 \mathrm{mmHg}$ with type B.

negative; the phase shift became positive at as low a frequency as about $8 \mathrm{~Hz}$. Essentially the same changes were obtained on CSNS with both stimulation types. Dog 9 (Fig. 5) had a lower prestimulation mean blood pressure and the heart was paced at a higher frequency ( 180 beats/min). On CSNS the change in resistance was less marked than in dog 8 . This also held for the impedance moduli and phase shift at low frequencies. The change in phase shift on CSNS was qualitatively the same as in $\operatorname{dog} 8$, however.

\section{DISCUSSION}

\section{On the transient responses to CSNS}

The observation by Hering (23) that the cardiac reflex induced by sinus baroreceptor stimulation had a more sudden onset than the vasomotor reflex, and that it was poorly maintained, initiated a large number of investigations with the aim of distinguishing between the cardiac effects caused by changes in vagal tone and those caused by changes in sympathetic tone. In many of these studies the one effect has been studied by elimination of the effector part of the other. Wang \& Borison (62), for instance, showed that a rapid effect on the heart rate was obtained by carotid sinus distension both in anatomically intact and in sympathectomized dogs, while the effect was slower in vagotomized dogs and completely absent in dogs that were both sympathectomized and vagotomized.

As an effect of a rapid increase in carotid sinus pressure, Koepchen et al. (37) found that the rapid change (within $1 \mathrm{~s}$ ) in heart beat interval was more marked at lower original heart rates. In determinations of the time delay of the heart rate response, Kalkoff \& Schneider (32) found that this delay diminished after local application of adrenaline to the carotid sinus and consequent reduction of the systemic blood pressure. The responses of the heart rate to initiation of CSNS (Fig. 1) were in accordance with the tindings of Koepchen et al. (37), more marked changes being noted at lower prestimulation heart rates. This effect, which was 
considered to be due to an increased vagal tone ( 37 , 38) was of short duration in dog 1. A gradual increase in heart rate occurred simultaneous with the increase in pulse pressure. This might indicate an interaction of other inputs, causing an increase in sympathetic tone.

Warner \& Cox (64), on stimulating the autonomous efferent nerves to the heart, noted an immediate response to vagal stimulation, while the sympathetic responses were slower.

On pressure stimulation of the carotid sinus baroreceptors Green (22) recorded an increase in the activity of the vagal efferents to the heart. Katona \& Barnett (33) found in similar studies that this increase occurred after a latency of $100 \mathrm{msec}$. When the blood pressure was lowered a decrease in vagal activity occurred after $300 \mathrm{~ms}$. With single pulse stimulation of the carotid sinus nerve Iriuchijima \& Kumada $(25,26)$ noted an increase in activity in the cardiac branches of the vagal nerve between 60 and $120 \mathrm{~ms}$ after delivery of the stimulation impulse. Stimulation of the sinus nerve at frequencies over $10 \mathrm{~Hz}$ induced profuse impulses in the cardiac vagus.

With CSNS, Seller \& Richter (60) obtained complete initial inhibition of the efferent sympathetic activity, occurring with a mean latency of $181 \mathrm{~ms}$. Their experiments were performed in dogs with both 'cervical-vagal-sympathetic trunks' cut. Adaptation of the sympathetic nerve activity took place in $30-40 \mathrm{~s}$. Studies by Glick \& Braunwald (21) and Robinson et al. (50) also indicated that the heart rate response to changes in arterial pressure might be preferentially vagal or sympathetic, depending on the pre-existing level of blood pressure and/or on the pre-existing level of vagal or sympathetic tone. The heart rate changes shown in Fig. 1 (left part) may suggest a temporal separation of the vagal and sympathetic effects on the heart, which would seem to agree with the findings discussed above. Dog 7 , which had a higher total peripheral resistance, a higher mean blood pressure and a higher heart rate than $\operatorname{dog} 1$ before stimulation, showed a more gradual decrease in heart rate.

Berkowitz et al. (4) found that vagotomy has no effect on the heart rate in dogs earlier submitted to bilateral stellatectomy and upper thoracic ganglionectomy. They suggested that the sympathetic tone thus was the major determinant of vagal tone, referring to the concept proposed by Rosenblueth \& Freeman (51) that reciprocal variations in both divisions of the autonomic system caused the changes in heart rate. In this study on CSNS at 15 $\mathrm{imp} / \mathrm{cardiac}$ cycle the rapid (vagus-mediated) change in heart rate was obtained even at a high prestimulation total peripheral resistance (Table I and Fig. 1, dogs 3 and 7) and the heart rate reduction was then better maintained, indicating a more marked inhibition of (high) sympathetic tone. Thus, at a high total peripheral resistance before CSNS the heart rate changes seem to be caused partly by an increased vagal tone (rapid effect) and partly by inhibition of the sympathetic tone (late effect). At a low prestimulation total peripheral resistance, the rapid vagal effects on the heart rate are more obvious.

The magnitude and steepness of the initial mean blood pressure reduction on CSNS varied, but when the mean blood pressure attained a level of $110-120 \mathrm{mmHg}$ an increase in pulse pressure occurred (see Fig. 1), indicating activity in other input pathways to the central nervous system. Sarnoff et al. (55), in experiments on vagotomized dogs in which the heart rate was kept constant, observed no similar change in pulse pressure on increasing the carotid perfusion pressure. In the present study, however, the transient response to CSNS did not change dramatically during pacing of the heart (cf, Fig. 2). As in the case without pacing, an increase in pulse pressure, coinciding with the maximum reduction in blood pressure, was observed.

A transient increase in cardiac output $(8.3 \%)$ and blood flow in the femoral artery $(40.0 \%)$ on electrical stimulation of the carotid sinus nerves was reported by Resnicoff et al. (49). The blood flow thereafter fell below the control values (by 19.7\%). In the present study a rapid decrease in blood flow in the femoral artery preceded the transient increase in all dogs except one $(\operatorname{dog} 3)$. At higher stimulation frequencies the blood flow sometimes failed to regain the prestimulation value and the oscillatory period then seemed shorter. In most experiments, however, a greater increase in blood flow was obtained in dogs with a low prestimulation TPR. In conscious dogs Vatner et al. (65) found that on CSNS (constant frequency; $50 \mathrm{~Hz}$ ) an average increase in femoral blood flow of $90 \%$ occurred in $30 \mathrm{~s}$. It seems therefore that large differences in blood flow response can be obtained under different experimental conditions. Moreover, differences in the blood flow response to CSNS under equivalent experimental conditions may be obtained, due to 
differences in the total peripheral resistance prior to stimulation.

\section{On the adaptation period}

The initial dramatic fall in blood pressure and heart rate on CSNS was partly restored within the first min (see Fig. 1). On continued stimulation, differences in the persistent heart rate effects of the stimulation were found with different stimulation types (Fig. 3). These were distinct at $5 \mathrm{imp} / \mathrm{cardiac}$ cycle in the period $5-10 \mathrm{~min}$ after the initiation of CSNS, and also during the first min of stimulation with $15 \mathrm{imp} /$ cardiac cycle. In a previous study $(29$, Figs. 8 and 10) the differences in heart rate reduction with different stimulation types were obvious at 5, 10, 15 and $25 \mathrm{imp} /$ cardiac cycle; in that study, however, the reduction was calculated as the mean for the first $30 \mathrm{~min}$ of stimulation.

After lowering the carotid sinus pressure and thereby diminishing the endogenous sinus nerve activity, the heart rate reduction on CSNS was almost equal with all stimulation types (29). However, in that experimental situation Öberg \& Sjöstrand (46) found that CSNS with impulse trains had a greater blood pressure reducing effect than stimulation at a constant frequency (see also Discussion on resistance).

In this study, on CSNS with $5 \mathrm{imp} /$ cardiac cycle, the blood pressure, heart rate and femoral blood flow were relatively stable 1,5-2 min after the start of stimulation. The resistance in the vascular bed of the femoral artery could thus be calculated $2 \mathrm{~min}$ after commencement of CSNS; at that time point the reductions in this resistance were 20.3 (stimulation type A), 19.7 (B) and 19.3 (C)\% of the prestimulation value. On comparing the resistance values at $2 \mathrm{~min}$ and those 5-10 min after the start of stimulation the latter were higher than the former by 10.1 (A), 8.4 (B) and 8.4 (C)\%. Thus in the period after 2 min of CSNS, the resistance in the vascular bed of the femoral artery seemed to increase with all types of stimulation, while at the same time the heart rate decreased only on stimulation with the intermittent types, suggesting that some other mechanism than sympathetic inhibition may have been involved.

In view of the fact that the differences in stroke volume with different stimulation types were small, the further heart rate reduction obtained with the intermittent stimulation types would seem to have been caused by increased parasympathetic influence on the S.A. node. Among possible mechanisms underlying the above findings, the differences in response latency in the effector parts of the autonomous nervous system on activation of the carotid sinus reflex should be considered. Of the asymmetries observed in the response of the blood pressure regulating system to step inputs to the carotid sinus, the findings of Katona \& Barnett (33) on vagal efferent activity seem of interest in discussions on the heart rate effect. Further, Scher \& Young (57) have reported that conscious, morphine-sedated dogs usually show entirely vagal responses (without phase lag) to repeated phasic increases of pressure stimulation of the baroreceptors. They also considered the greater phase lag in response to a decreased pressure to be due to stronger influence of the sympathetic nervous system.

The differences in initial heart rate reduction with different stimulation frequencies have been discussed in previous articles $(30,31)$. The gradual increase in heart rate during continued CSNS also seemed to be influenced by the stimulation frequency (Fig. 4), an observation which may be related to the duration of the initially complete inhibition of sympathetic activity at the onset of CSNS (60). This inhibition lasted somewhat longer at higher stimulation frequencies. However, if CSNS with $15 \mathrm{imp} / \mathrm{impulse}$ train really does increase the vagal efferent activity as an effect of every impulse burst, at least during the first min, in the same way as single impulse stimulation of the carotid sinus nerve (26) or as single step pressure input to the carotid sinus (33), the slow adaptation of the heart rate may reflect the recovery of the sympathetic tone. In this connection the findings of Bronk et al. (5) and Folkow (18) on transmission of stimulation impulses in sympathetic ganglia are of interest. According to Folkow (18), high frequency stimulation of the first member in a link of neurons will cause a higher than normal discharge rate in the last neuron. This might be the neurophysiological basis for the described differences in heart rate effects during the whole period of stimulation.

As mentioned above, the differences in heart rate reduction between intermittent and constant frequency CSNS were obtained only in dogs with intact vagal nerves and with no clamping of the common carotid arteries. A low prestimulation sympathetic tone might be a prerequisite for these different effects of CSNS on the heart rate. The asymmetries in the autonomic effector action on the 
S.A. node might constitute the underlying mechanism for these differences.

In the unanaesthetized dog (31), however, the effects of CSNS on the blood pressure and heart rate were more marked during work than during rest. In considering the effects of CSNS in unanaesthetized dogs the influence of spontaneous ventilation on vagal efferent activity $(25,27)$ and sympathetic activity $(1,5,59)$ and that of muscle contraction on sympathetic activity (13) must be taken into account. The greater heart rate reductions obtained with intermittent stimulation of the carotid sinus nerves in anaesthetized dogs were probably counteracted by the interaction of other inputs in the unanaesthetized dogs [see also (58)].

\section{Blood flow and cardiac output on CSNS}

Carlsten et al. (8) showed that on electrical stimulation of the carotid sinus nerves in man the forearm blood flow increased, and they considered this effect to be due to symphathetic inhibition. Vasodilatation in the perfused gracilis muscle and a simultaneous inhibition of lumbar sympathetic activity on CSNS were shown by Seller et al. (59). They found, moreover, that the vasodilatation was greater during the expiratory phase.

In studying the intact circulatory system Resnicoff et al. (49) found on correlative analysis that the femoral vascular bed was the only vascular bed to manifest an increase in blood flow on carotid sinus nerve stimulation. In the present study it was only at lower stimulation frequencies that the blood flow in the femoral artery comprised an increased proportion of the cardiac output on CSNS. At the higher stimulation frequencies such a change was counteracted by the greater reductions in heart rate and mean blood pressure.

The earliest reports on the effects of activation of the carotid sinus reflex on cardiac output varied considerably. Some authors found that it was unchanged, while others reported an increase of up to $100 \%$. Kenney et al. (34) found no reduction in cardiac output or heart rate on electrical stimulation of the carotid sinus nerves in dogs anaesthetized with thiopental sodium and with intact vagal nerves. In pentobarbital anaesthetized dogs Resnicoff et al. (49) observed a reduction in cardiac output of 3.9 per cent on CSNS. In unanaesthetized dogs Vatner et al. (65) noted an initial transient increase in cardiac output on CSNS which regained the control value after $15-20 \mathrm{~s}$. These discrepant results might be due to differences in the experimental conditions (cf. 12). It has been shown (9) that during pentobarbital anaesthesia the cardiac output decreased considerably when the arterial $\mathrm{pH}$ was lowered. In the present study the ventilation was kept adequate (HFPPV) and the acid base status was checked repeatedly. Further, it has been shown (10) that no significant changes in cardiac output persist $60 \mathrm{~min}$ after induction of chloralose anaesthesia. Dogs under this anaesthesia are hypertensive and exhibit exaggerated baroreceptor reflexes (6). The magnitude of the reduction in cardiac output obtained in this study should be regarded in relation to the marked reductions in heart rate during chloralose anaesthesia.

CSNS did not alter the stroke volume except in the experiments with cardiac pacing; here it decreased significantly with all types of stimulation but more markedly with the intermittent types. The effect of CSNS on stroke volume in these experiments should be considered in relation to the prevailing heart rate and the sympathetic tone, as no changes in either ventricular contractility (54) or excitability (53) were observed on increasing the vagal tone. The stroke volume changes on CSNS during pacing of the heart indicate that the time relation of the heart events (54) and the contractility (55) are affected by CSNS-induced alterations in sympathetic tone. This is also supported by the finding of Dunning (14) that pacing of the heart in man caused a rapid increase in tension time index and ventricular $\mathrm{dp} / \mathrm{dt}$; during CSNS at a constant frequency these effects of pacing were more retarded.

\section{On total peripheral resistance and regional vascular resistance}

The concept of resistance has often been utilized in studies of the vascular tone in skeletal muscle (cf. $18,24,39$ ). In these studies the pressure difference has been kept constant. Calculations of peripheral resistance both as total and as regional values have been made in several investigations under conditions of changes in both pressure and flow $(34,49$, 65 , among others). It should be pointed out that the calculated peripheral resistance under these conditions not only reflects changes in vascular tone but is an expression of the relation of pressure to flow, which may be affected by differences in the size and constitution of the experimental animal used (cf. 34). In most vascular beds the pressure-flow rela- 
tionship is non-linear and the possible existence of critical opening pressures in some beds may also influence the vascular resistance (20). The measurement of peripheral resistance under these circumstances may be justified in studies of the circulatory system when comparing the effects of different quantified signals to the central nervous system.

It is important that the measures used in studies with calculation of peripheral resistance should not markedly alter the venous tone (19). Browse et al. (7) found minor transient changes in venous tone during 'extreme stimulation' with pressure activation of the carotid sinus baroreceptors. In the present study CSNS caused only a slight and transient change in central venous pressure which was concomitant with the initial reductions in blood pressure and heart rate. This is also in accordance with the observations of Epstein et al. $(16,17)$, who found that CSNS had no effect on the venous tone or central venous pressure.

As the heart does not eject blood directly into the vessels which determine the peripheral resistance, calculations of this variable during transient events, e.g. the initial blood pressure and blood flow reactions to CSNS (Figs. 1 and 2) are greatly affected by capacitive phenomena caused by the large distensible arteries. For this reason resistance calculations in the present study were performed during periods of steady state before and during CSNS.

The observed initial responses of heart rate and blood flow (Figs. 1 and 2 and the related text) illustrate the importance of investigating the prestimulation conditions of the dog. The magnitude of the response in different dogs seems to be related to the prestimulation total peripheral resistance in spite of the errors involved in the concept of peripheral resistance mentioned above. Minor variations in prestimulation TPR between the different sequences in each dog constituted a control which allowed comparison of the effects of subsequent measures.

The change in total peripheral resistance obtained on CSNS was significant with all stimulation types used in this study, but smaller than that reported by Resnicoff et al. (49). This should be considered in the light of the difference in mean prestimulation TPR between the two studies [Resnicoff et al. (49); $0.10 \mathrm{mmHg} / \mathrm{ml} / \mathrm{min}$; present study: 0.070 (S.E. 0.007$) \mathrm{mmHg} / \mathrm{ml} / \mathrm{min}$ ]. This may be due at least partially to the differences in anaesthesia (pentobarbital and chloralose, respectively), as discussed above. Similarly, the resistance in the vascular bed of the femoral artery was also lower in this study both before and during CSNS in comparison with the values reported by Resnicoff et al. (49).

Heymans \& Bouchaert showed at an early date $(1929,1932$; see 24$)$ that the cerebral blood vessels do not participate actively in the baroreceptor reflexes. In the present study the minor changes in resistance in the vascular bed of the carotid artery reflect its partly autoregulatory properties.

The alteration in resistance in the vascular bed of the femoral artery was almost the same with all stimulation types, both at 5 and $15 \mathrm{imp} /$ cardiac cycle. This was also true during pacing of the heart (see Table II). The previously observed greater reductions in blood pressure with intermittent impulse train stimulation of the carotid sinus nerves in dogs with clamped common carotid arteries (46), are in accordance with the findings of Seller et al. (59) in vagotomized dogs. In the present study the differences in blood pressure reactions to constant frequency and intermittent stimulation were negligible. The differences in experimental situations may support the view that the previously noted greater reductions in blood pressure with intermittent stimulation are only obtained in the preexistence of a high sympathetic tone.

\section{Vascular input impedance}

As the most obvious characteristic of arterial blood flow is its pulsatile nature, several investigations have been made on the pulse wave and its velocity (cf. 42, 47). McDonald (41) suggested that the term impedance should be used when pulsatile pressure and flow in arteries are considered and that resistance should be confined to steady flow. He also introduced the concept of input impedance, which is "the pressure-flow relation at the input artery to a vascular bed in the presence of reflections". The input impedance is obtained by calculating the ratio between each of the harmonic frequency components of the oscillatory pressure and flow (43).

Randell \& Stacey (48) were the first to measure the input impedance of the vascular bed of the femoral artery. McDonald (42) produced changes in the input impedance of this artery by vasoconstriction and vasodilatation. In an extensive study, 
O'Rourke \& Taylor (52) analysed a large number of pressure and flow waves both at constant heart rates (pacing) and at variable heart rates. They noted changes in input impedance and in the reflection of the pressure wave on intraarterial injection of vasoconstrictor and vasodilator drugs and found support for the assumption that the major reflection sites are in the arterioles. According to Gessner (20) the known non-linearities (elasticity as a function of transmural pressure; non-linear hydrodynamic phenomena) seem to have little influence on impedance.

In this study the aim of calculating input impedance was to find out whether carotid sinus nerve stimulation would cause the same changes in impedance as intraarterial injection of vasodilator drugs, and whether any differences would be obtained with different stimulation patterns.

In contrast to earlier studies of input impedance, an experimental situation without ventilationsynchronous variations in blood pressure was achieved by the use of HFPPV (28). The heart rate was kept constant by atrial pacing. Since no changes in either pulse or flow waves were obtained on measuring subsequent cycles at steady state, data from one cycle alone were used for the impedance calculations. The numerical harmonic analysis was performed according to Manley (44).

Resynthesis of the blood pressure and blood flow waves by a computer (61) almost completely recovered the original curves when the Fourier coefficients were used for the first six harmonics (58). This reflects the accuracy of the method despite the fewness of the sampling points.

The changes in input impedance obtained in $\operatorname{dog} 8$ (cf. Fig. 4) are very similar to those obtained by McDonald (42) and O'Rourke \& Taylor (52) after intraarterial injection of a vasodilator (acetylcholine), and lie in the opposite direction to those resulting from a vasoconstrictor (noradrenalin). In $\operatorname{dog} 9$ (Fig. 5), which had a lower prestimulation mean blood pressure, the changes in impedance moduli and phase shift on CSNS were smaller but lay in the same direction as in $\operatorname{dog} 8$. No differences with regard to the type of stimulation applied were noted.

It seems probable that carotid sinus nerve stimulation causes a reflex vasodilator effect giving rise to changes in the input impedance of the femoral artery, which persist for at least $5 \mathrm{~min}$ after the start of stimulation.

\section{CONCLUSIONS}

The results of this study show that the differences in effect of stimulating the carotid sinus nerves with impulses of constant frequency and with intermittent impulse trains, with the same number of impulses per cardiac cycle, are small, both as regards the blood flow in the common carotid and in the femoral artery, and as regards the stroke volume and regional peripheral resistance. The initial change in blood flow in the femoral artery is dependent primarily on the total peripheral resistance prior to stimulation and secondarily on the stimulation frequency.

The study verifies previously reported differences in heart rate reduction with different stimulation types, and shows that the decrease in cardiac output follows that in heart rate. During atrial pacing, CSNS reduces the stroke volume.

Calculation of the input impedance of the vascular bed of the femoral artery indicates that the impedance changes on CSNS are similar to those observed earlier on intraarterial injection of vasodilator drugs.

The asymmetries in the autonomic effects on the S.A. node of the heart are discussed as a reason for the differences in heart rate reduction on constant frequency and intermittent stimulation of the carotid sinus nerves. These effects are only obtained in dogs with intact vagal nerves and no clamping of the common carotid arteries.

\section{ACKNOWLEDGEMENTS}

The study was supported financially by grants from the Swedish Board of Technical Development, Stockholm (projects 70-439/U370, 70-1495/U1111, 71-1783/U1353 and $72-522 / \mathrm{U} 435$ ), the Medical Faculty of the University of Uppsala, the O. \& E. Ericsson Research Fund, Atvidaberg, the Medical Research Fund of Förenade Liv Insurance Co., Stockholm, the Swedish Society for Medical Research and the Swedish Medical Research Council (Project No. B75-61P-4566-01).

The author thanks U.-B. Berg, H. Billander, B. Fors, G. Montin, G. Nilsson, S. Norberg, M. Ohlsson, B. Westerberg and B. Östmark for valuable technical assistance and E. Arnelund, M. Lundin and E. Tåhlin for preparing the manuscript.

\section{REFERENCES}

1. Adrian, E. D., Bronk, D. W. \& Philips, G.: Discharges in mammalian sympathetic nerves. $\mathrm{J}$ Physiol 74: $115,1932$. 
2. Balis, G. U. \& Monroe, R. R.: The pharmacology of chloralose, A review. Psychopharmacologia 6: 1, 1964.

3. Bergel, D. \& Makin, G.: Experience with calibration procedures. In New Findings in Blood Flowmetry (ed. Chr. Cappelen Jr), pp. 99-103. Universitetsforlaget, Oslo, 1968.

4. Berkowitz, W. D., Scherlag, B. J., Stein, F. \& Damato, A. N.: Relative roles of sympathetic and parasympathetic nervous systems in the carotid sinus reflex in dogs. Circulat Res 24: 447, 1969.

5. Bronk, D. W., Tower, S. S., Solandt, D. Y. \& Larrabee, M.G.: The transmission of trains of impulses through a sympathetic ganglion and in its postganglionic nerves. Am J Physiol 122: 1, 1938.

6. Brown, R. V. \& Hilton, J. G.: Baroreceptor reflexes in dogs under chloralose anesthesia. J Pharmacol Exptl Therap 118: 198, 1956.

7. Browse, N. L., Donald, D. E. \& Shepherd, J. T.: Role of the veins in the carotid sinus reflex. Am $\mathbf{J}$ Physiol 210: $1424,1966$.

8. Carlsten, A., Folkow, B., Grimby, G., Hamberger, C.-A. \& Thulesius, O.: Cardiovascular effects of direct stimulation of the carotid sinus nerve in man. Acta Physiol Scand 44: 138, 1958.

9. Carson, S. A. A., Gordon, E. C., Hamilton, F. N., Lee, D. C. \& Morris, L. E. Variation in cardiac output with acid-base changes in the anesthetized dog. J Appl Physiol 20: 948, 1965.

10. Cox, R. H.: Influence of chloralose anaesthesia on cardiovascular function in trained dogs. Am J Physiol $3: 660,1972$.

11. Dedichen, H. \& Schenk, W. G., Jr: Influence of hematocrit changes on square-wave electromagnetic flowmeter calibration. In New Findings in Blood Flowmetry (ed. Chr. Cappelen Jr), pp. 104-106. Universitetsforlaget, Oslo, 1968.

12. Delaunois, A. L. \& Bernard, P. J.: Cardiac output during carotid sinus reflexes. In Baroreceptors and Hypertension (ed. P. Kezdi), pp. 181-185. Pergamon Press, London, 1967.

13. Delius, W., Hagbarth K.-E., Hongell, A. \& Wallin, B. G.: Manoeuvres affecting sympathetic outflow in human skin nerves. Acta Physiol Scand 84: 177, 1972.

14. Dunning, A. J.: Electrostimulation of the carotid sinus nerve in angina pectoris. Excerpta Medica 1971.

15. Enghoff, E., Michaelsson, M., Pavek, K. \& Sjögren, S.: A comparison between the thermal dilution method and the direct Fick and the dye dilution methods for cardiac output measurements in man. Acta Soc Med Upsal 75: 157, 1970.

16. Epstein, S. E., Beiser, G. D., Stampfer, M. \& Braunwald, E.: Role of the venous system in baroreceptor-mediated reflexes in man. J Clin Invest 46: $139,1968$.

17. Epstein, S. E., Beiser, G. D., Goldstein, R. E., Stampter, M., Wechsler, A. S., Glick, G. \& Braunwald, E.: Circulatory effects of electrical stimulation of the carotid sinus nerves in man. Circulation 40:269, 1969.
18. Folkow, B.: Impulse frequency in sympathetic vasomotor fibres correlated to the release and elimination of the transmitter. Acta Physiol Scand 25:49, 1952.

19. - Nervous control of blood vessels. Physiol Rev $35: 629,1955$.

20. Gessner, U.: Vascular input impedance. In Cardiovascular Fluid Dynamics (ed. D. H. Bergel), pp. 315-350. Academic Press, London and New York, 1972.

21. Glick, G. \& Braunwald, E.: Relative roles of the sympathetic and parasympathetic and nervous systems in the reflex control of heart rate. Circulat Res 16: 363, 1965.

22. Green, J. H.: Cardiac vagal efferent activity in the cat. Am J Physiol 149:47P, 1959.

23. Hering, H. E.: Die Karotissinus Reflexe auf Herz und Gefässe. Steinkopff, Leipzig, 1927.

24. Heymans, C. \& Neil, E.: Reflexogenic Areas of the Cardiovascular System. J. \& A. Churchill Ltd. London, 1958.

25. Iriuchijima, J. \& Kumada, M.: Efferent cardiac vagal discharge of the dog in response to electrical stimulation of sensory nerves. Jap J Physiol 13: 599, 1963.

26. - Activity of single vagal fibres efferent to the heart. Jap J Physiol 14: 479, 1964.

27. Jewett, D. L.: Activity of single efferent fibres in the cervical vagus nerve of the dog, with special reference to possible cardio-inhibitory fibres. J Physiol 175:321, 1964.

28. Jonzon, A., Öberg, P. A., Sedin, G. \& Sjöstrand, U.: High frequency positive pressure ventilation by endotracheal insufflation. Acta Anaesth Scand, Suppl. 43, 1971.

29. - Studies of blood-pressure regulation. IV. The effects of impulse-train stimulation of the carotid sinus nerves. Acta Physiol Scand 85: 323, 1972.

30. - Studies of blood-pressure regulation in the unanaesthetized dog. I. The effects of constant frequency stimulation of the carotid-sinus nerves. Pflügers Arch 340: 211, 1973.

31. - Studies of blood-pressure regulation in the unanaesthetized dog. II. The effects of impulse train stimulation of the carotid-sinus nerves. Pflügers Arch 340: 229, 1973.

32. Kalkoff, W. \& Schneider, H. M.: Zeitbedarfsänderungen des.Herz- under Kreislaufreflexes durch lokale Applikation von Adrenalinlösung am Karotissinus. Acta Biol Med Germ 22: 561, 1969.

33. Katona, P. G. \& Barnett, G. O.: Central origin of asymmetry in the carotid sinus reflex. Ann NY Acad Sci 156: $779,1969$.

34. Kenney, R. A., Neil, E. \& Schweitzer, A.: Carotid sinus reflexes and cardiac output in dogs. J Physiol $114: 27,1951$.

35. Kezdi, P.: Baroreceptors \& Hypertension (ed. P. Kezdi). Pergamon Press, London, 1967.

36. Koch, E.: Die Reflektorische Selbsteuerung des Kreislaufes. Steinkopff, Leipzig, 1931.

37. Koepchen, H. P., Lux, H. D \& Wagner, P. H.: Untersuchungen über Zeitbedarf und zentrale Verarbeitung des pressoreceptorischen Herzreflexes. Pflügers Arch 273: 413, 1961. 
38. Koepchen, H. P., Wagner, P. H. \& Lux, H. D.: Über die Zusammenhänge zwischen zentraler Erregbarkeit, reflektorischem Tonus und Atemrythmus bei der nervösen Steuerung der Herzfrequenz. Pflügers Arch 273: 443, 1961.

39. Koepchen, H. P., Seller, H. \& Polster, J.: Hochempfindliche Wiederstandregistrierung bei kleinen Flussen. Pflügers Arch 294: 72, 1967.

40. Levison, W. H., Barnett, G. O. \& Jackson, W. D.: Nonlinear analysis of the baroreceptor reflex system. Circulat Res 18:673, 1966.

41. McDonald, D. A.: The relation of pulsatile pressure to flow in arteries. J Physiol 127: 533, 1955.

42. - Blood Flow in Arteries. Edward Arnold Publishers Ltd., London, 1960.

43. - Frequency dependence of vascular impedance. In Pulsatile Blood Flow (ed. E. O. Attinger), pp. 115-134. McGraw-Hill Book Company, New York, 1964.

44. Manley, R. G.: Waveform Analysis. Chapman \& Hall Ltd, London, 1945.

45. Öberg, P. A. \& Sjöstrand, U.: Studies of bloodpressure regulation. II. On-line simulation as a method of studying the regulatory properties of the carotid sinus reflex. Acta Physiol Scand 75: 287, 1969.

46. - Studies of blood-pressure regulation. III. Dynamics of arterial blood pressure on carotid-sinus nerve stimulation. Acta Physiol Scand 81:96, 1971.

47. Porjé, I. G.: Studies of the arterial pulse wave, particularly in the aorta. Acta Physiol Scand 13: Suppl. 42, 1946.

48. Randell, J, E. \& Stacey, R. W.: Mechanical impedance of the dog's hind leg to puisatile blood flow. Am J Physiol 187: 94, 1956.

49. Resnicoff, S. A., Harris, J. P., Hampsey, J. P. \& Schwartz, S. I.: Effects of sinus nerve stimulation on arterial resistance and flow patterns of specific vascular beds. Surgery 66: 755, 1969.

50. Robinson, B. F., Epstein, S. E., Beiser, G. D. \& Braunwald, E.: Control of heart rate by the autonomic nervous system. Circulat Res 19: 400, 1966.

51. Rosenblueth, A. \& Freeman, N. E.: The reciprocal innervation in reflex changes of heart rate. Am J Physiol 98:430, 1931.

52. O'Rourke, M. F. \& Taylor, M. G.: Vascular impedance in the femoral bed. Circulat Res 18: 126, 1966.

53. Samuelsson, R. \& Sjöstrand, U.: Studies on myocardial excitation of the right ventricle of the dog heart in situ. Acta Physiol Scand 85:477, 1972.

54. Sarnoff, S. J., Brockman, S. K., Gilmore, J. P., Linden, R. J. \& Mitchell, J. H.: Regulation of ventricular contraction. Circulat Res 8: 1108, 1960.

55. Sarnoff, S. J., Gilmore, J. P., Brockman, S. K., Mitchell, J. H. \& Linden, R. J.: Regulation of ventricular contraction by the carotid sinus. Circulat Res 8: 1123, 1960.

56. Scher, A. M. \& Young, A. C.: Servoanalysis of carotid sinus reflex effects on peripheral resistance. Circulat Res $12: 152,1963$.

57. - Reflex control of heart rate in the unanaesthetized dog. Am J Physiol 218: 780, 1970.
58. Sedin, G.: Cardiovascular responses to carotid sinus nerve stimulation. Dissertation. Acta Univ Upsal. $146,1973$.

59. Seller, H., Langhorst, P., Richter, D. \& Koepchen, H. P.: Über die Abhängigkeit der pressoreceptorischen Hemmung der Sympathicus von der Atemphase und ihre Auswirkung in der Vasomotorik. Pflügers Arch $302: 300,1968$.

60. Seller, H. \& Richter, D. W.: Some quantitative aspects of the central transmission of the baroreceptor activity. In Research in Physiology (ed. F. F. Kao, K. Koizumi \& M. Vassalle), pp. 541-549. A. Gaggi Publ., Bologna, 1971.

61. Teorell, T.: Personal communication, 1972.

62. Wang, S. C. \& Borison, H. L.: An analysis of the carotid sinus cardiovascular reflex mechanism. Am J Physiol 150: 712, 1947.

63. Warner, H. R.: The frequency-dependent nature of blood pressure regulation by the carotid sinus studied with an electric analogue. Circulat Res $6: 35,1958$.

64. Warner, H. R. \& Cox, A.: A mathematical model of heart rate control by sympathetic and vagus efferent information. J Appl Physiol 17:349, 1962.

65. Vatner, S. F., Franklin, D., Van Citters, R. L. \& Braunwald, E.: Effects of carotid sinus nerve stimulation on blood-flow distribution in conscious dogs at rest and during exercise. Circulat Res 27: 495, 1970.

Received June 24, 1975

Address for reprints:

Gunnar Sedin, M. D.

Institute of Physiology and

Medical Biophysics

Biomedical Center

University of Uppsala

Box 572

S-751 23 Uppsala 